Sharif University of Technology
Scientia Iranica
Transactions E: Industrial Engineering
http://scientiairanica.sharif.edu
IRA I ENTIA

\title{
A fuzzy solution approach to supplier selection and order allocation in green supply chain considering the location-routing problem
}

\author{
Z. Ebrahimi Qazvinia ${ }^{a}$ A. Haji ${ }^{b, *}$, and H. Mina ${ }^{c}$ \\ a. Department of Industrial Engineering, Faculty of Engineering, Payam Noor University, Tehran, Iran. \\ b. Department of Industrial Engineering, Faculty of Industrial Engineering, Sharif University of Technology, Tehran, Iran. \\ c. School of Industrial Engineering, College of Engineering, University of Tehran, Tehran, Iran.
}

Received 17 April 2018; received in revised form 21 May 2019; accepted 2 July 2019

KEYWORDS
Supplier selection;
Order allocation;
Mathematical
modelling;
Analytic hierarchy
process;
Fuzzy theory.

\section{KEYWORDS}

Supplier selection;

modelling;

Analytic hierarchy

process;

Fuzzy theory.

\begin{abstract}
In the field of supply chain, selecting a suitable green supplier could significantly help us decrease the cost and risks of the operations and increase the quality of green supply. This paper develops an integrated two-stage approach based on Fuzzy Analytic Hierarchy Process (FAHP) and multi-objective mixed-integer linear programming to select suppliers and allocate order in the green supply chain. In the first stage, suppliers are evaluated using FAHP method and in the second stage, a multi-product multi-period supply chain is developed considering green location-routing problem, discounting, and time window under uncertainty. Then, a fuzzy solution approach is applied to solve the proposed model using the data of a pharmaceutical chain in Iran. Results will verify the efficiency of the proposed model.
\end{abstract}

(C) 2021 Sharif University of Technology. All rights reserved.

\section{Introduction}

Deteriorating effect of excessive exploitation of natural resources on the environment is one of the obvious results of growing world population. For instance, over the last few years, on average, 30000 million tons of carbon dioxide has been produced [1]. Designing a green supply chain is one of the principal approaches to alleviating the mentioned destructive effect. A green supply chain protects the environment while increasing the competitiveness of organizations through integration of financial information and logistics $[2,3]$. A while after the proposition of green supply chain, many

*. Corresponding author:

E-mail address: ahaji@sharif.edu (A. Haji)

doi: $10.24200 /$ sci.2019.50829.1885 organizations have prioritized environmental issues and modified their operations accordingly [3]. The first step to this end is to purchase an environmentally-friendly raw material [4]. For manufacturing companies, approximately $70 \%$ of the cost of a product is related to its raw material [5]. Therefore, pursuing purchasing strategies in green supply chain management is vital and significant.

More specifically, the concurrent selection of appropriate suppliers and satisfaction of multiple criteria such as price, quality, delivery, risk, innovation, flexibility, green, etc. have turned the purchasing procedure into a critical challenge [6].

Decision-making literature shows that considering multiple criteria that oppose each other will yield a Multiple-Criteria Decision-Making (MCDM) problem [7-10]. It is called MCDM because of the many competing criteria in the supplier selection 
problem [11,12]. Moreover, this complexity increases upon adding environmental concerns to this already complicated problem. There are numerous studies in the literature that use MCDM methods for green supplier selection and order allocation [3,13-16].

MCDM process is divided into two parts: Multiple Attribute Decision-Making (MADM) and Multiple Objective Decision-Making (MODM). In most of the studies, the MADM approach is used for supplier evaluation (with qualitative criteria) and MODM approach is used to assign order allocation and other quantitative decisions [17]. One of the widely applied MADM methods in supplier evaluations is Analytic Hierarchy Process (AHP) $[18,19]$.

The Analytic Network Process (ANP) [20,21], the Technique for Order Preference by Similarity to Ideal Solution (TOPSIS) [22,23], Visekriterijumska Optimizacija I Kompromisno Resenje (VIKOR) [2426], the Decision-Making Trial and Evaluation Laboratory (DEMATEL) $[27,28]$ and the Best-Worst Method (BWM) [3] are other MADM methods adopted in the suppliers evaluation process. Also, Linear Programming (LP) [29], Mixed Integer Linear Programming (MILP) [30,31], Fuzzy Multi-Objective Linear Programming (FMOLP) [3], Multi-Objective Mixed Integer Linear Programming (MOMILP) [32], MultiObjective Mixed Integer Non-Linear Programming (MOMINLP) [16,33], and goal programming [34] are common MODM methods. These methods have been used in the field of supplier selection and order allocation. The more we know about these methods and on how they could be combined for a specific problem, the better we conduct research in this area.

A review of the related literature shows that many studies have investigated supplier selection so far. Some of these studies have focused only on supplier selection (strategic approach), while some others have considered order allocation and supplier selection (strategic and operational approaches). Hence, this paper develops a hybrid two-stage approach based on Fuzzy Analytic Hierarchy Process (FAHP) and MOMILP for supplier selection and order allocation in green supply chain considering the location-routing problem under demand uncertainty. Therefore, the proposed model will be considered in this study in which such assumptions as multi-period, multiproduct, multi-depot, capacitated and green locationrouting problems, discounting on purchase, storage, shortage, and other common assumptions are included. To the best of our knowledge, it is notable that these assumptions concerning supplier selection and order allocation problem have not been simultaneously considered in any other studies so far.

In the following, Sections 2 and 3 introduce the literature review and the proposed approach, respectively. Section 4 is dedicated to the application of the proposed model to the company under study. Section 5 presents sensitivity analysis. The final section is allocated to the conclusion.

\section{Literature review}

The challenging competitions and globalization of today's markets have converted supplier selection to one of the most significant decisions made by decisionmakers [35]. Supplier selection problem has been an enticing theme for research since 1960 [5]. There has been a wealth of review papers in this domain such as De Boer et al. [36], Aissaoui et al. [37], Ho et al. [38], Ware et al. [39], Chai et al. [40], Igarashi et al. [41], Govindan et al. [42], Zimmer et al. [43], and Keshavarz Ghorabaee et al. [44].

Studies in the field of supplier selection can be mainly divided into three categories: supplier evaluation and selection, order allocation, and combination of both [3]. In this research, the papers on the green supplier selection and order allocation are reviewed.

Mafakheri et al. [45] employed the AHP to determine criteria weights and scores for suppliers. They also used a bi-objective mathematical model and a solution approach based on dynamic programming for order allocation. The objective functions simultaneously minimize costs and maximize the purchase value. Four main criteria of price, delivery, quality, and environmental performance were defined for supplier evaluation.

Shaw et al. [46] employed a combined approach made up of FAHP and FMOLP for supplier selection and order allocation problem in order to minimize greenhouse gas emissions. They applied the model to a garment manufacturing company in India for model validation.

Kannan et al. [13] developed an integrated approach based on FAHP, Fuzzy TOPSIS (FTOPSIS), and MOLP for supplier selection and order allocation in green supply chain management. They measured the performance of each supplier based on the cost, quality, delivery, technology capability, and environmental competency criteria using a combination of FAHP and FTOPSIS methods. Then, the obtained scores were used as factors in the objective function of maximizing purchases from fitting suppliers. The other objective function was to minimize the total cost of purchasing.

Using three environmental criteria including environmental management system, pollution and greenhouse emissions, along with other criteria, Azadnia et al. [47] utilized the FAHP method to evaluate suppliers. They developed a multi-objective programming model for allocating orders to suppliers.

Govindan and Sivakumar [14] proposed an MOLP model for simultaneously minimizing costs, minimizing defective product purchases, minimizing delays 
in products delivery, minimizing recycling losses, and minimizing carbon emissions. They used fuzzy TOPSIS method to calculate the factors of each objective function.

An integrated approach as integration of FAHP, FTOPSIS, and multi-objective mathematical models was developed by Hamdan and Cheaitou [15]. They took into account the traditional and green criteria and quantity discount. The resulting multi-objective problem was solved using a weighted comprehensive criterion method and branch-and-cut algorithm. Similar to this approach, Hamdan and Cheaitou $[48,49]$ integrated AHP, FTOPSIS, and multi-objective programming model approaches to solve supplier selection and order allocation problem, taking both traditional and green criteria into account.

Mohammed et al. [17] used a four-phased approach to sustainable supplier selection and order allocation. In the first phase, the weight of criteria was calculated using FAHP and in the second phase, FTOPSIS was used to calculate the scores assigned to suppliers. The third phase was devoted to the development of a multi-objective programming model and finally, in the fourth phase, the Pareto solutions were presented using the TOPSIS.

A hybrid approach based on BWM, FTOPSIS, and fuzzy multi-objective linear programming model was developed by Lo et al. [3] for selecting suppliers and allocating orders. Using BWM, they calculated the weight of the criteria and then, used FTOPSIS to rank suppliers. Finally, by using a FMOLP model, the orders were allocated to suppliers.

Babbar and Amin [50] employed an MOLP model by considering environmental issues in the supplier selection and order allocation problem. To this end, they used a novel fuzzy quality function development model to determine the weights of suppliers and then, developed a stochastic MOLP model for order allocation.

An integrated three-part approach to sustainable supplier selection and order allocation was presented by Gören [27] considering lost sales. In the first part of the proposed approach, the weights of the criteria were calculated by the fuzzy DEMATEL. The obtained weights were considered as input of the second part and the scores given for suppliers were calculated by Taguchi loss function. Finally, in the third section, the proposed order allocation method was proposed. Cheraghalipour and Farsad [30] presented a hybrid approach based on multi-criteria decision-making and the MILP model for sustainable supplier selection and order allocation. They investigated two types of discounts on purchases from suppliers and disruption risks. In their proposed approach, the economic, environmental, and social scores for each supplier were calculated using BWM and then, they were placed as purchasing objective function coefficients from sustained suppliers. In another objective function, the total cost was minimized.

\section{Problem statement and proposed approach}

Designing a supply chain network with regard to strategic and operational decisions is critically important. In this paper, a hybrid approach based on FAHP and MOMILP model is developed for designing a green supply chain network by considering supplier selection and order allocation problem. The proposed approach consists of two stages. In the first stage, due to the hierarchical relationship between factors and lack of interdependence among them, FAHP method is applied to the evaluation and selection of suppliers. In the next stage, an MOMILP model is developed in which such assumptions as multi-period, multiproduct, multi-depot, capacitated and green locationrouting problems, discounting on purchase, storage, and shortage under uncertainty are considered.

One of the benefits of the proposed approach is that the performance of each supplier affects the selection process and cost is the only factor that does not influence the selection of suppliers. One of the other benefits of the proposed approach is the possibility of designing a network from the highest level of supply chain (supplier) to the lowest level (customer) considering the real-world assumptions. This approach is explained in the following.

\subsection{First stage: Supplier evaluation}

At this stage, suppliers are analyzed and ranked such that the qualified suppliers can be selected. To this end, one FAHP is applied in the following manner:

Step 1: A comprehensive set of common and green criteria is derived from a review of the related literature and inclusion of experts' opinions to analyze the suppliers.

Step 2: FAHP has been used according to the experts' opinions and due to a very low degree of innerdependence between the criteria and sub-criteria and the hierarchical structure among them. Experts will conduct a pairwise comparison between factors based on the linguistic terms shown in Table 1. Once the questionnaire was filled out and the pairwise comparison matrix derived, the local weight of each factor would be calculated by a non-linear model, as explained in Eq. (1). This model was proposed by Dağdeviren and Yüksel [51].

\section{$\max \lambda$}

$$
\begin{aligned}
& \text { s.t.: } \\
& \left(m_{i j}-l_{i j}\right) \times \lambda \times w_{j}-w_{i}+l_{i j} \times w_{j} \leq 0,
\end{aligned}
$$


Table 1. Linguistic scale for difficulty and importance.

\begin{tabular}{cccc}
\hline $\begin{array}{c}\text { Linguistic scales } \\
\text { for difficulty }\end{array}$ & $\begin{array}{c}\text { Linguistic scales } \\
\text { for importance }\end{array}$ & $\begin{array}{c}\text { Triangular fuzzy } \\
\text { scale }\end{array}$ & $\begin{array}{c}\text { Triangular fuzzy } \\
\text { reciprocal scale }\end{array}$ \\
\hline Just equal & Just equal & $(1,1,1)$ & $(1,1,1)$ \\
Equally difficult & Equally important & $(1 / 2,1,3 / 2)$ & $(2 / 3,1,2)$ \\
Weakly more difficult & Weakly more important & $(1,3 / 2,2)$ & $(1 / 2,2 / 3,1)$ \\
Strongly more difficult & Strongly more important & $(3 / 2,2,5 / 2)$ & $(2 / 5,1 / 2,2 / 3)$ \\
Very strongly more difficult & Very Strongly more important & $(2,5 / 2,3)$ & $(1 / 3,2 / 5,1 / 2)$ \\
Absolutely more difficult & Absolutely more important & $(5 / 2,3,7 / 2)$ & $(2 / 7,1 / 3,2 / 5)$ \\
\hline
\end{tabular}

Table 2. Linguistic values and mean of fuzzy numbers.

\begin{tabular}{cccc}
\hline $\begin{array}{c}\text { Linguistic values } \\
\text { for positive } \\
\text { sub-factors }\end{array}$ & $\begin{array}{c}\text { Linguistic values } \\
\text { for negative } \\
\text { sub-factors }\end{array}$ & $\begin{array}{c}\text { Triangular } \\
\text { fuzzy numbers }\end{array}$ & $\begin{array}{c}\text { The mean of } \\
\text { fuzzy numbers }\end{array}$ \\
\hline Very weak & Very strong & $(0,0,0)$ & 0 \\
Weak & Strong & $(0,0.167,0.333)$ & 0.167 \\
Weak-mid & Mid-strong & $(0.167,0.333,0.5)$ & 0.333 \\
Mid & Mid & $(0.333,0.5,0.667)$ & 0.5 \\
Mid-strong & Weak-mid & $(0.5,0.667,0.833)$ & 0.667 \\
Strong & Weak & $(0.667,0.833,1)$ & 0.833 \\
Very strong & Very weak & $(1,1,1)$ & 1 \\
\hline
\end{tabular}

$$
\begin{aligned}
& \left(u_{i j}-m_{i j}\right) \times \lambda \times w_{j}+w_{i}-u_{i j} \times w_{j} \leq 0, \\
& \sum_{k=1}^{n} w_{k}=1, \\
& w_{k} \geq 0 \\
& k=1,2, \ldots, n, \\
& i=1,2, \ldots, n-1, \\
& j=2,3, \ldots, n .
\end{aligned}
$$

In the non-linear model, $(l, m, u)$ represent the lowest, the most, and the largest possible values of triangular fuzzy numbers in pairwise comparisons, respectively, and $w_{k}$ represents the $k$ th criterion weight. The parameters $i$ and $j$ show the row and column of the pairwise comparison matrix, respectively, and $n$ denotes the number of criteria.

The optimal value of $\lambda$ may be equal to a positive or negative number. A positive $\lambda$ shows consistency in the pairwise comparison matrix, whereas a negative $\lambda$ shows inconsistency in pairwise comparison matrix; thereby, the experts should be warned to reconsider their judgments.

Based on the proposed model, the total weight of the criteria should be equal to 1 and the weight of each criterion should be a positive number. Also, to complete the comparison pairs matrix, only the top of the diameter should be completed, which will reduce the number of pair comparisons.

Once the model has been solved, the local weight of each of the criteria and sub-criteria can be achieved. Then, the local weight of criteria should be applied to the local weight of sub-criteria in order to determine the global weight of each sub-criterion.

Step 3: In this step, the score for each supplier in each factor needs to be determined. For this purpose, experts are asked to score the related factors in each supplier using the linguistic terms given in Table 2 . The triangular fuzzy numbers equivalent to linguistic terms are used in this step, as presented in Table 2 [51].

In doing so, the average of experts' opinions is calculated for each supplier in terms of each subcriterion. Therefore, those suppliers with acceptable scores will move on to the second stage as qualified suppliers.

\subsection{Second stage: Supply chain network design}

At this phase, the multi-echelon supply chain including supply, distribution, and demand is at play. To design a supply chain with maximum desirable performance, 
an integrated chain with a desirable performance has been decided to be designed while achieving optimal policies at a micro level, especially in the fields of supplier selection, transportation planning, location, purchase planning, etc. In addition, the optimal parameters of the mentioned system at a macro level were determined. Hence, the aim is to make a wide range of decisions including strategic policies from selecting suitable suppliers and finding suitable locations to making operational decisions such as routing of vehicles and transferred products. The assumptions about the proposed model are as follows:

\section{Assumptions:}

- The intended supply chain in this research includes supply, distribution, and demand levels;

- The supply chain considered is of multi-product and multi-period type;

- The location of distribution centers is determined by the model;

- Vehicles have been considered heterogeneous;

- The number and capacity of vehicles used for transportation are determined;

- The time needed for the movement of vehicles is absolutely predetermined;

- The storage has been considered in the model;

- The vehicles routing problem lies between distribution and demand levels;

- The routing problem has been considered to be multi-depot;

- Taking the purchasing discount from suppliers has been considered;

- The rate of demand has been considered to be fuzzy;

- Time windows constraint has been considered in the proposed model;

- It is possible to encounter shortages that are considered as lost demand.

The following is a description of the proposed model:

\section{Indices:}

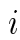$$
s
$$$$
d
$$$$
c, \hat{c} \quad \text { Customer }(1 \leq c \leq C)
$$$$
k \quad \text { Price level }(1 \leq k \leq K)
$$$$
\nu \quad \text { Vehicle }(1 \leq v \leq V)
$$

$t \quad$ Time period $(1 \leq t \leq T)$

\section{Parameters:}

$c p_{\text {pat }}^{\text {sup }} \quad$ Capacity of supplier $a$ for product $p$ in time period $t$

$c p_{p b t}^{d s t} \quad$ Capacity of distribution center $b$ for product $p$ in time period $t$

$c p_{m}^{\nu h} \quad$ Capacity of vehicle $\nu$

$f l w_{p a b} \quad$ Maximum shipment flow of product $p$ from supplier $a$ to distribution center $b$

$d s_{i j}^{c s} \quad$ Location distance of customer $i$ from customer $j$

$t m_{m i j}^{c s}$

$d s_{b j}$

$t m_{m b j}$

$c s t_{b}^{d s t}$

$c s t_{m}^{v h}$

$c s t_{\text {padt }}^{\text {trn }}$

Time distance of customer $i$ from customer $j$ by vehicle $m$

Location distance of distribution center $b$ from customer $j$

Time distance of distribution center $b$ from customer $j$ by vehicle $m$

Setup cost of distribution center $b$

Supply cost of vehicle $m$

Transportation cost of each unit of product $p$ from supplier $a$ to distribution center $b$ in time period $t$

$d m_{p j t}$

$h l d_{p t}$

Demand of customer $j$ for product $p$ in time period $t$

Holding cost of each unit of product $p$ in time period $t$

$f_{m} \quad$ Fuel consumption of vehicle $m$ per unit of distance

$w_{a} \quad$ Weight (green score) of supplier $a$ (achieved from FAHP)

prc plat Purchase price per unit of product $p$ from supplier $a$ at price level $l$ in time period $t$

ord $_{a t} \quad$ Ordering cost to supplier $a$ in time period $t$

$A_{\text {plat }} \quad$ The upper bound volume of purchased product $p$ from supplier $a$ in time period $t$ at price level $l$

$\varphi \quad$ Time window

$c^{\text {fuel }} \quad$ Price per unit of fuel

bigm $\sim \infty \quad$ Big number

Variables:

$x_{b}^{d s t} \begin{cases}1 & \text { If distribution center } b \text { is launched } \\ 0 & \text { Otherwise }\end{cases}$

$x_{m}^{\nu h} \begin{cases}1 & \text { If vehicle } m \text { is supplied } \\ 0 & \text { Otherwise }\end{cases}$ 
$x_{m i j t} \begin{cases}1 & \text { If vehicle } m \text { moves from customer } \\ & \text { to customer } j \text { in time period } t \\ 0 & \text { Otherwise }\end{cases}$

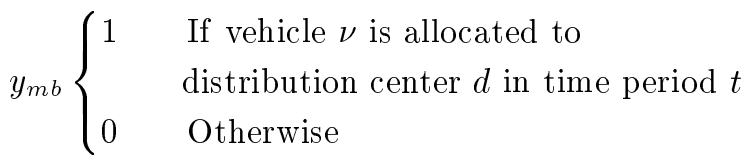

$x_{\text {plat }}^{\text {sup }} \begin{cases}1 & \text { If product } p \text { supplied from supplier } \\ & \text { a at price level } l \text { in time period } t \\ 0 & \text { Otherwise }\end{cases}$

$a t_{m j t} \quad$ Arrival time of vehicle $m$ to location of customer $j$ in time period $t$ (Positive)

invtry $y_{p j t}^{p} \quad$ The number of products $p$ available in the stock of customer $j$ in time period $t$ (Positive)

invtry ${ }_{p j t}^{n}$ The amount of shortage of product $p$ for customer $j$ in time period $t$ (Positive)

invtry $_{p j t}$ Inventory (Free)

$z_{p m b j t} \quad$ The number of products $p$ transferred from distribution center $b$ by vehicle $m$ to customer $j$ in time period $t$ (Positive)

$\theta_{\text {plabt }} \quad$ The number of products $p$ purchased from supplier $a$ by distribution center $b$ at the price level $l$ in time period $t$ (Positive)

\section{Mathematical model}

Objective function

$$
\begin{aligned}
\min Z^{\text {cost }}= & c^{\text {fuel }} \times f_{m} \times\left(\sum_{m, i>1, j>1, t} x_{m i j t}\right. \\
& \times d s_{i j}^{c s}+\sum_{m, b, j, t}\left(x_{m 1 j t}+x_{m j 1 t}\right) \\
& \left.\times y_{m b} \times d s_{b j}\right)+\sum_{p, l, a, b, t} \theta_{p l a b t} \times c s t_{p a d t}^{t r n} \\
& +\sum_{m} x_{m}^{\nu h} \times c s t_{m}^{\nu h}+\sum_{p, j, t} h l d_{p t} \\
& \times i n v t r y_{p j t}^{p}+\sum_{p, l, a, b, t} p_{p r c} c_{p l a t} \times \theta_{p l a b t} \\
& +\sum_{p, l, a, t} \text { ord }_{a t} \times x_{p l a t}^{\text {sup }}+\sum_{b} c s t_{b}^{d s t} \times x_{b}^{d s t} .(2)
\end{aligned}
$$

First objective function: Minimizing the total costs of chain. These costs include transportation cost, the cost of holding products in the customer's stock, product supply cost, and distribution center location cost.

$$
\max Z^{\text {purchasevalue }}=\sum_{p, l, a, b, t} w_{a} \times \theta_{\text {plabt }} .
$$

Second objective function: Maximizing the value of purchases from qualified suppliers.

Subjected to:

$$
\begin{aligned}
& \sum_{l, b} \theta_{\text {plabt }} \leq c p_{\text {pat }}^{\text {sup }} \quad \forall p, a, t, \\
& \sum_{l, a} \theta_{\text {plabt }} \leq c p_{p b t}^{d s t} \quad \forall p, b, t, \\
& \sum_{l, a, b} \theta_{\text {plabt }} \leq \sum_{a, b} f l w_{p a b} \quad \forall p, t .
\end{aligned}
$$

Non-exceedance of supplier capacity, distribution center capacity, and product flow capacity among them are represented in Constraints (4) to (6), respectively.

$$
\sum_{p, j} z_{p m b j t} \leq c p_{m}^{\nu h} \quad \forall m, b, t .
$$

Constraint (7) states that the number of products delivered by a vehicle should not exceed the capacity.

$$
\sum_{l, a} \theta_{\text {plabt }} \geq \sum_{m, j} z_{p m b j t} \quad \forall p, b, t .
$$

The total number of products delivered from suppliers to distribution centers in each period should not be less than that of the products delivered from centers to customers, as explained in Constraint (8).

$$
\begin{aligned}
& \sum_{p, b, j} z_{p m b j t} \leq \text { bigm } \times \sum_{b} y_{m b} \quad \forall m, t \\
& \sum_{b} y_{m b} \leq 1 \quad \forall m .
\end{aligned}
$$

According to Constraint (9), products are delivered to customers by vehicles provided that the vehicle is allocated to one distribution center. According to Constraint (10), each vehicle is allocated to only one distribution center.

$$
\sum_{m} y_{m b} \leq b i g m \times x_{b}^{d s t} \quad \forall b .
$$

According to Constraint (11), a vehicle cannot be allocated to the distribution center unless the center has been located.

$$
\sum_{m, i} x_{m i j t} \leq 1 \quad \forall j, t .
$$

Each customer can be visited only by one vehicle, as shown in Constraint (12). 


$$
\sum_{i} x_{m i j t}=\sum_{i} m_{m j i t} \quad \forall m, j, t .
$$

According to Constraint (13), if we enter one customer location, we should exit.

$$
\begin{aligned}
& a t_{m j t}+b i g m \times\left(1-x_{m i j t}\right) \geq\left(a t_{m i t}+t m_{m i j}^{c s}\right) \\
& \forall m, i, j>1, t \\
& \varphi+b i g m \times\left(1-x_{m j 1 t}\right) \geq a t_{m j t}+\sum_{b} t m_{m b j} \times y_{m b}
\end{aligned}
$$

$$
\forall m, j, t
$$

Sub-tour elimination constraint and arrival time to each customer location are calculated using Constraints (14) and (15). Also, Constraint (15) shows the non-exceedance of time window for perishable products.

$$
\begin{aligned}
& \sum_{p, b} z_{p m b j t} \leq b i g m \times \sum_{i} x_{m i j t} \quad \forall m, j, t \\
& \sum_{p, b, j} z_{p m b j t} \leq b i g m \times x_{m}^{\nu h} \quad \forall m, t .
\end{aligned}
$$

The product will be delivered to the customers if and only if the vehicle visits them and that the vehicle has already been supplied. This issue is justified in Constraints (16) and (17), respectively.

$$
\begin{aligned}
\text { invtry }_{p j t} & =\sum_{m, b} z_{p m b j t}+i n v t r y_{p j(t-1)}-d m_{p j t} \\
\forall p, j, t & >1 \\
\text { invtry }_{p j t} & =\sum_{m, b} z_{p m b j t}-d m_{p j t} \quad \forall p, j, t=1 .
\end{aligned}
$$

Constraints (18) and (19) are related to stock balance in customers' warehouses.

$$
\text { invtry }_{p j t}=i n v t r y_{p j t}^{p}-i n v t r y_{p j t}^{n} \quad \forall p, j, t .
$$

Determining inventory and dealing with shortages are done in Constraint (20).

$$
\begin{gathered}
\sum_{m, b, t} z_{p m b j t}=\sum_{t} d m_{p j t} \\
\forall p, j .
\end{gathered}
$$

Constraint (21) enforces the model to meet all demands from customers at the end of the final period. Hence, it does not allow a lost demand to occur.

$$
\begin{gathered}
\theta_{\text {plabt }}+\text { bigm } \times\left(1-x_{\text {plat }}^{\text {sup }}\right) \geq A_{\text {plat }} \\
\forall p, l, a, b, t \\
\theta_{\text {plabt }} \leq A_{p(l+1) a t}+\text { bigm } \times\left(1-x_{\text {plat }}^{\text {sup }}\right)
\end{gathered}
$$$$
\forall p, l, a, b, t \text {. }
$$

Constraints (22) and (23) are applied in the step pertaining to discount on purchasing products from suppliers.

$$
\sum_{l} x_{\text {plat }}^{\text {sup }} \leq 1 \quad \forall p, a, t .
$$

Finally, Constraint (24) indicates that it is possible to purchase products from each supplier in each time period at only one price level.

\subsubsection{Linearization process}

In order to apply the linearization process, the following auxiliary variables are defined based on which the linear equivalents are presented for each nonlinear phrase [52]:

$$
x y_{m b i j t}\left\{\begin{array}{l}
1 \\
0
\end{array} \quad\right. \text { Binary }
$$

Nonlinear equation:

$$
\begin{aligned}
\min Z^{\text {cost }}= & c^{\text {fuel }} \times f_{m} \times\left(\sum_{m, i>1, j>1, t} x_{m i j t}\right. \\
& \times d s_{i j}^{c s}+\sum_{m, b, j, t}\left(x_{m 1 j t}+x_{m j 1 t}\right) \\
& \left.\times y_{m b} \times d s_{b j}\right)+\sum_{p, l, a, b, t} \theta_{p l a b t} \times c s t_{p a d t}^{t r n} \\
& +\sum_{m} x_{m}^{\nu h} \times c s t_{m}^{\nu h}+\sum_{p, j, t} h l d_{p t} \times i n v t r y_{p j t}^{p} \\
& +\sum_{p, l, a, b, t} p r c_{p l a t} \times \theta_{p l a b t}+\sum_{p, l, a, t} \text { ord }_{a t} \\
& \times x_{\text {plat }}^{\text {sup }}+\sum_{b} c s t_{b}^{d s t} \times x_{b}^{d s t} .
\end{aligned}
$$

Linear equation:

$$
\begin{aligned}
\min Z^{\text {cost }}= & c^{\text {fuel }} \times f_{m} \times\left(\sum_{m, i>1, j>1, t} x_{m i j t} \times d s_{i j}^{c s}\right. \\
& \left.+\sum_{m, b, j, t}\left(x y_{m b 1 j t}+x y_{m b j 1 t}\right) \times d s_{b j}\right) \\
& +\sum_{p, l, a, b, t} \theta_{p l a b t} \times c s t_{p a d t}^{\text {trn }}+\sum_{m} x_{m}^{\nu h}
\end{aligned}
$$




$$
\begin{gathered}
\times c s t_{m}^{\nu h}+\sum_{p, j, t} h l d_{p t} \times i n v t r y_{p j t}^{p} \\
+\sum_{p, l, a, b, t} p r c_{p l a t} \times \theta_{p l a b t}+\sum_{p, l, a, t} \text { ord } d_{a t} \\
\times x_{p l a t}^{\text {sup }}+\sum_{b} c s t_{b}^{d s t} \times x_{b}^{d s t} \\
x y_{m b i j t} \leq y_{m b}+\left(1-x_{m i j t}\right) \times \text { bigm } \\
x y_{m b i j t} \leq x_{m i j t}+\left(1-y_{m b}\right) \times b i g m \\
x y_{m b i j t} \geq 1+\left(x_{m i j t}+y_{m b}-2\right) \times b i g m \\
x y_{m b i j t} \leq\left(x_{m i j t}+y_{m b}\right) \times b i g m
\end{gathered}
$$

\subsection{Solution approach}

Among different approaches used for dealing with uncertainty in optimization problems, Fuzzy Theory is the most popular method [53]. Depending on the specification of a given problem, different fuzzy approaches have been developed in literature [54-58]. The method which was developed by Zimmermann [54] and Lin [56] allows converting a multi-objective problem to a single-objective problem considering the uncertainty in the objective function and constraint. The solution approach is presented as follows:

$$
\begin{aligned}
& \max \alpha \\
& \text { S.t. : } \\
& \alpha \leq \mu_{z_{k}^{\min }}(x), \\
& \alpha \leq \mu_{z_{r}^{\max }}(x), \\
& \alpha \leq \mu_{g_{l}}(x) .
\end{aligned}
$$

These membership functions are defined as follows:

$$
\begin{aligned}
& \mu_{Z_{k}^{\min }}(x)= \\
& \left\{\begin{array}{c}
1 \quad z_{k}(x)>z_{k}^{\text {positive }} \\
0 \quad z_{k}(x)<z_{k}^{\text {negative }} \\
f_{\mu_{z_{k}^{\text {min }}}}=\frac{z_{k}^{\text {positive }}-z_{k}(x)}{z_{k}^{\text {positive }}-z_{k}^{\text {negative }}} \\
z_{k}^{\text {negative }} \leq z_{k}(x) \leq z_{k}^{\text {positive }}
\end{array}\right. \\
& \mu_{Z_{l}^{\min }}(x)= \\
& \left\{\begin{array}{c}
1 \quad z_{l}(x)>z_{l}^{\text {positive }} \\
0 \quad z_{l}(x)<z_{l}^{\text {negative }} \\
f_{\mu_{z_{l}^{\text {min }}}}=\frac{z_{l}(x)-z_{l}^{\text {negative }}}{z_{l}^{\text {positive }}-z_{l}^{\text {negative }}}, \\
z_{l}^{\text {negative }} \leq z_{l}(x) \leq z_{l}^{\text {positive }}
\end{array}\right.
\end{aligned}
$$

$$
\begin{aligned}
& \mu_{g_{l}}(x)= \\
& \begin{cases}1 & g_{l}(x)>b_{l} \\
0 & g_{l}(x)<b_{l}+d_{l} \\
f_{Z_{l}^{\max }}=\frac{1-\left[g_{l}(x)-b_{l}\right]}{d_{l}}, & b_{l} \leq g_{l}(x) \leq b_{l}+d_{l}\end{cases}
\end{aligned}
$$

where the value of the objective function $z_{k}\left(z_{l}\right)$ varies from the lower bound $z_{k}^{\text {negative }}\left(z_{l}^{\text {negative }}\right)$ to upper bound $z_{k}^{\text {positive }}\left(z_{l}^{\text {positive }}\right) ; \mu_{z_{k}^{\min }}(x), \mu_{z_{r}^{\max }}(x)$ and $\mu_{g_{l}}(x)$ represent the membership functions of maximum, minimum, and constraints, respectively. $b_{l}$ and $d_{l}$ are the $l$ th crisp or fuzzy value and a tolerance value, respectively.

\section{Case study}

Pharmaceutical Distribution Companies are active in the areas of the supply and distribution of human pharmaceuticals, purchase and sale of human pharmaceuticals, medical equipment, import and export of human pharmaceuticals, investment in the manufacturing, distribution of human pharmaceuticals, etc. The main objectives of such companies are providing the required human pharmaceuticals both in Iran and the region, improving customers' and shareholders' satisfaction, promoting the distribution quality of pharmaceuticals, and increasing the company's share in the local provision and supply of human pharmaceuticals.

In this paper, the proposed model has been applied to assess the effectiveness and validation of a pharmaceutical company in the city of Tehran. The studied company produces and distributes more than 20 types of drugs. Three drugs are produced by the same production line and hence, hold similar data. Because of this similarity, these three drugs have been chosen for the study. Using expert opinion and the availability of the chain data under study, we implemented the model for 3 perishable goods, 6 suppliers, 3 distribution center locations, 3 vehicles, 4 price levels, and 6 time periods. The stages required for the implementation are as follows:

\subsection{First stage: Supplier evaluation 4.1.1. Step 1:}

In this step, the criteria and sub-criteria for supplier evaluation and selection were extracted based on a review of the related literature and experts' experiences in the chain under study. To this end, three criteria, namely greenness, quality, and delivery and service were selected. The sub-criteria under these three criteria are given in Table 3 .

\subsubsection{Step 2:}

According to experts' opinions, given the low level of inner-dependence among the criteria, FAHP was 
Table 3. Criteria and sub-criteria for supplier evaluation.

\begin{tabular}{|c|c|c|}
\hline Criteria & Sub-criteria & References \\
\hline \multirow{8}{*}{ Green } & Environmental management system (G1) & Luthra et al. [59], Fallahpour et al. [60] \\
\hline & Green packaging (G2) & Fallahpour et al. [60], Büyüközkan and Çifçi [61] \\
\hline & Hazardous wastes (G3) & Kannan et al. [62] \\
\hline & Green technology (G4) & Fallahpour et al. [60] \\
\hline & Green design and purchasing (G5) & Luthra et al. [59] \\
\hline & Air emission (G6) & Mina et al. [20], Noci [63], \\
\hline & & Humphreys et al. [64], Lee et al. [65] \\
\hline & Eco-design (G7) & Fallahpour et al. [60], Handfield et al. [66] \\
\hline \multirow{3}{*}{ Quality } & Quality of product (Q1) & Luthra et al. [59] \\
\hline & Capability of handling abnormal quality (Q2) & Lee et al. [65] \\
\hline & Product rejection rate (Q3) & Feyziogg̃lu and Büyüközkan [67] \\
\hline \multirow{3}{*}{$\begin{array}{c}\text { Delivery } \\
\text { and service }\end{array}$} & On-time delivery (D1) & Mina et al. [20], Luthra et al. [59] \\
\hline & Lead time flexibility (D2) & Fallahpour et al. [60], Yang and $\mathrm{Wu}[68]$ \\
\hline & Time to solve the complaint (D3) & Fallahpour et al. [60], Yang and $\mathrm{Wu}[68]$ \\
\hline
\end{tabular}

Table 4. Pairwise comparison matrix among criteria.

\begin{tabular}{cccc}
\hline Criteria & Green & Quality & Delivery and service \\
\hline Green & $(1,1,1)$ & $(1 / 2,2 / 3,1)$ & $(1 / 2,2 / 3,1)$ \\
Quality & $(1,3 / 2,2)$ & $(1,1,1)$ & $(1,1,1)$ \\
Delivery and service & $(1,3 / 2,2)$ & $(1,1,1)$ & $(1,1,1)$ \\
\hline
\end{tabular}

applied to determine their weights. Therefore, the local weights of all criteria and sub-criteria were determined using the proposed nonlinear model, as in the pairwise table filled out by experts with linguistic terms (Table 1).

The results obtained from the substitution of triangular fuzzy numbers for linguistic terms in pairwise comparisons are given in Tables 4 to 7 .

In order to calculate the local weights of criteria and sub-criteria, the nonlinear model of Dağdeviren and Yüksel [51] and the pairwise comparison data are used as the parameters. For example, the nonlinear model is converted into the following form using the data given in Table 4 . Thus, criteria weights are obtained by solving the model in GAMS24.1/CONOPT.

\section{$\max \lambda$}

s.t. :

$\frac{1}{6} \times \lambda \times w_{2}-w_{1}+\frac{1}{2} \times w_{2} \leq 0$,

$\frac{1}{3} \times \lambda \times w_{2}+w_{1}-w_{2} \leq 0$, 
Table 5. Pairwise comparison matrix among green sub-criteria.

\begin{tabular}{cccccccc}
\hline $\begin{array}{c}\text { Green sub- } \\
\text { criteria }\end{array}$ & G1 & G2 & G3 & G4 & G5 & G6 & G7 \\
\hline G1 & $(1,1,1)$ & $(1,3 / 2,2)$ & $(1,3 / 2,2)$ & $(1 / 2,1,3 / 2)$ & $(1 / 2,1,3 / 2)$ & $(1,3 / 2,2)$ & $(3 / 2,2,5 / 2)$ \\
G2 & $(1 / 2,2 / 3,1)$ & $(1,1,1)$ & $(1,3 / 2,2)$ & $(1 / 2,2 / 3,1)$ & $(1,3 / 2,2)$ & $(1,3 / 2,2)$ & $(3 / 2,2,5 / 2)$ \\
G3 & $(1 / 2,2 / 3,1)$ & $(1 / 2,2 / 3,1)$ & $(1,1,1)$ & $(1 / 2,2 / 3,1)$ & $(1 / 2,2 / 3,1)$ & $(1,3 / 2,2)$ & $(3 / 2,2,5 / 2)$ \\
G4 & $(2 / 3,1,2)$ & $(1,3 / 2,2)$ & $(1,3 / 2,2)$ & $(1,1,1)$ & $(1 / 2,2 / 3,1)$ & $(1,3 / 2,2)$ & $(3 / 2,2,5 / 2)$ \\
G5 & $(2 / 3,1,2)$ & $(1 / 2,2 / 3,1)$ & $(1,3 / 2,2)$ & $(1,3 / 2,2)$ & $(1,1,1)$ & $(1,3 / 2,2)$ & $(1,3 / 2,2)$ \\
G6 & $(1 / 2,2 / 3,1)$ & $(1 / 2,2 / 3,1)$ & $(1 / 2,2 / 3,1)$ & $(1 / 2,2 / 3,1)$ & $(1 / 2,2 / 3,1)$ & $(1,1,1)$ & $(1 / 2,1,3 / 2)$ \\
G7 & $(2 / 5,1 / 2,2 / 3)$ & $(2 / 5,1 / 2,2 / 3)$ & $(2 / 5,1 / 2,2 / 3)$ & $(2 / 5,1 / 2,2 / 3)$ & $(1 / 2,2 / 3,1)$ & $(2 / 3,1,2)$ & $(1,1,1)$ \\
\hline
\end{tabular}

Table 6. Pairwise comparison matrix among quality sub-criteria.

\begin{tabular}{cccc}
\hline $\begin{array}{c}\text { Quality sub- } \\
\text { criteria }\end{array}$ & Q1 & Q2 & Q3 \\
\hline Q1 & $(1,1,1)$ & $(2 / 3,1,2)$ & $(1 / 2,1,3 / 2)$ \\
Q2 & $(1 / 2,1,3 / 2)$ & $(1,1,1)$ & $(1,3 / 2,2)$ \\
Q3 & $(2 / 3,1,2)$ & $(1 / 2,2 / 3,1)$ & $(1,1,1)$ \\
\hline
\end{tabular}

Table 7. Pairwise comparison matrix among delivery and service sub-criteria.

\begin{tabular}{cccc}
\hline $\begin{array}{c}\text { Delivery and service } \\
\text { sub-criteria }\end{array}$ & D1 & D2 & D3 \\
\hline D1 & $(1,1,1)$ & $(1,3 / 2,2)$ & $(3 / 2,2,5 / 2)$ \\
D2 & $(1 / 2,2 / 3,1)$ & $(1,1,1)$ & $(2 / 3,1,2)$ \\
D3 & $(2 / 5,1 / 2,2 / 3)$ & $(1 / 2,1,3 / 2)$ & $(1,1,1)$ \\
\hline
\end{tabular}

Table 8. Local weights of criteria and sub-criteria and global weights of sub-criteria.

\begin{tabular}{cccc}
\hline $\begin{array}{c}\text { Criteria } \\
\text { (local weight) }\end{array}$ & Sub-criteria & Local weight & Global weight \\
\hline & G1 & 0.204 & 0.051 \\
Green (0.25) & G3 & 0.148 & 0.037 \\
& G4 & 0.14 & 0.035 \\
& G5 & 0.148 & 0.037 \\
& G6 & 0.123 & 0.037 \\
Quality (0.375) & G7 & 0.09 & 0.03075 \\
& Q1 & 0.335 & 0.0225 \\
\hline \multirow{2}{*}{ Delivery and service $(\mathbf{0 . 3 7 5 )}$} & Q2 & 0.379 & 0.1425625 \\
& Q3 & 0.286 & 0.10725 \\
\hline & D1 & 0.465 & 0.174375 \\
& D3 & 0.291 & 0.109125 \\
& & 0.244 & 0.0915 \\
\hline
\end{tabular}

$$
\begin{aligned}
& \frac{1}{6} \times \lambda \times w_{3}-w_{1}+\frac{1}{2} \times w_{3} \leq 0, \\
& \frac{1}{3} \times \lambda \times w_{3}+w_{1}-w_{3} \leq 0 \\
& -w_{2}+w_{3} \leq 0, \quad w_{2}-w_{3} \leq 0, \\
& w_{1}+w_{2}+w_{3}=1
\end{aligned}
$$

Therefore, the local weights of all criteria and subcriteria are calculated and the results are shown in Table 8. In order to obtain global weights of the subcriteria, local weights of criteria are applied in local weights of their sub-criteria. The results are given in Table 8.

4.1.3. Step 3:

In this step, suppliers are individually evaluated in 
Table 9. The final score of suppliers.

\begin{tabular}{ccccccc}
\hline Supplier & Supplier 1 & Supplier 2 & Supplier 3 & Supplier 4 & Supplier 5 & Supplier 6 \\
\hline Final score & 0.608558 & 0.558433 & 0.516702 & 0.620516 & 0.474682 & 0.487581 \\
\hline
\end{tabular}

Table 10. Customers demand per time period.

\begin{tabular}{llllllll}
\hline \multicolumn{1}{c}{$\boldsymbol{d}_{\boldsymbol{p} \boldsymbol{j} \boldsymbol{t}}$} & $\boldsymbol{t}=\mathbf{1}$ & $\boldsymbol{t}=\mathbf{2}$ & $\boldsymbol{t}=\mathbf{3}$ & $\boldsymbol{t}=\mathbf{4}$ & $\boldsymbol{t}=\mathbf{5}$ & $\boldsymbol{t}=\mathbf{6}$ \\
\hline$i=1$ & $c=1$ & 300 & 300 & 500 & 300 & 800 & 400 \\
$i=1$ & $c=2$ & 700 & 300 & 800 & 600 & 700 & 700 \\
$i=1$ & $c=3$ & 600 & 500 & 400 & 900 & 400 & 500 \\
$i=1$ & $c=4$ & 400 & 900 & 500 & 300 & 700 & 400 \\
$i=1$ & $c=5$ & 600 & 400 & 400 & 80 & 400 & 300 \\
$i=1$ & $c=6$ & 800 & 800 & 800 & 900 & 500 & 300 \\
$i=2$ & $c=1$ & 800 & 400 & 400 & 900 & 700 & 300 \\
$i=2$ & $c=2$ & 600 & 600 & 700 & 400 & 500 & 600 \\
$i=2$ & $c=3$ & 800 & 400 & 500 & 300 & 900 & 500 \\
$i=2$ & $c=4$ & 500 & 900 & 600 & 800 & 800 & 900 \\
$i=2$ & $c=5$ & 900 & 700 & 300 & 500 & 400 & 700 \\
$i=2$ & $c=6$ & 700 & 800 & 400 & 600 & 400 & 600 \\
$i=3$ & $c=1$ & 700 & 300 & 400 & 900 & 700 & 800 \\
$i=3$ & $c=2$ & 500 & 400 & 700 & 700 & 500 & 300 \\
$i=3$ & $c=3$ & 900 & 800 & 900 & 500 & 500 & 900 \\
$i=3$ & $c=4$ & 500 & 900 & 900 & 400 & 300 & 300 \\
$i=3$ & $c=5$ & 700 & 900 & 400 & 300 & 600 & 500 \\
$i=3$ & $c=6$ & 300 & 800 & 500 & 900 & 500 & 400 \\
\hline
\end{tabular}

terms of each sub-criterion. To this end, experts are asked to score each supplier on each sub-criterion by using linguistic terms of Table 2. The results of the final score are given in Table 9 .

According to the experts' opinions, the supplier who obtains the least score of 0.5 should enter the second stage as a qualified supplier. Thus, suppliers $1,2,3$, and 4 will be selected as qualified suppliers.

\subsection{Second stage: Supply chain network design}

This subsection consists of three parts. In the first part, data gathering will be dealt with and some of the most important parameters will be presented. In the second part, the proposed solution approach is applied and the single-objective fuzzy model is presented. The third part is dedicated to results and discussions.

\subsubsection{Data gathering}

In this part, some of the parameters corresponding to the case study are presented. Three perishable products, four selected suppliers, three potential distribution centers, four price levels, six customers, and six time periods are considered in validating the proposed model. Tables 10 to 12 show the most important parameters of the case study.

\subsubsection{Applying the solution approach}

In this section, by using the solution approach presented by Zimmermann [54] and Lin [56], the proposed model will be transformed into a single-objective model under uncertain demand. In doing so, the upper and lower bounds of each objective function are calculated as follows:

$$
\begin{aligned}
& z_{1}^{\text {negative }}=0, \\
& z_{2}^{\text {negative }}=0 \\
& z_{1}^{\text {positive }}=994703700, \\
& z_{2}^{\text {positive }}=2943 .
\end{aligned}
$$


Table 11. Transportation cost between suppliers and distribution centers.

\begin{tabular}{|c|c|c|c|c|c|c|c|c|c|c|c|c|c|}
\hline \multirow[t]{2}{*}{$c s t_{p a d t}^{t r n}$} & & $i=1$ & $i=1$ & $i=1$ & $i=1$ & $i=2$ & $i=2$ & $i=2$ & $i=2$ & $i=3$ & $i=3$ & $i=3$ & $i=3$ \\
\hline & & $s=1$ & $s=2$ & $s=3$ & $s=4$ & $s=1$ & $s=2$ & $s=3$ & $s=4$ & $s=1$ & $s=2$ & $s=3$ & $s=4$ \\
\hline$d=1$ & $t=1$ & 690 & 680 & 860 & 820 & 760 & 780 & 690 & 610 & 760 & 760 & 600 & 630 \\
\hline$d=1$ & $t=2$ & 660 & 730 & 880 & 890 & 660 & 650 & 830 & 840 & 580 & 800 & 590 & 620 \\
\hline$d=1$ & $t=3$ & 580 & 700 & 840 & 590 & 640 & 870 & 680 & 890 & 550 & 810 & 840 & 630 \\
\hline$d=1$ & $t=4$ & 640 & 830 & 840 & 870 & 560 & 560 & 880 & 630 & 780 & 600 & 560 & 660 \\
\hline$d=1$ & $t=5$ & 620 & 760 & 740 & 660 & 710 & 670 & 780 & 710 & 600 & 850 & 730 & 830 \\
\hline$d=1$ & $t=6$ & 630 & 810 & 700 & 760 & 760 & 560 & 770 & 810 & 680 & 640 & 690 & 840 \\
\hline$d=2$ & $t=1$ & 870 & 770 & 780 & 740 & 670 & 730 & 840 & 690 & 790 & 610 & 560 & 810 \\
\hline$d=2$ & $t=2$ & 760 & 550 & 600 & 630 & 640 & 630 & 900 & 860 & 890 & 600 & 800 & 700 \\
\hline$d=2$ & $t=3$ & 740 & 830 & 550 & 820 & 670 & 760 & 700 & 590 & 600 & 560 & 720 & 550 \\
\hline$d=2$ & $t=4$ & 620 & 800 & 750 & 740 & 720 & 890 & 560 & 900 & 830 & 790 & 660 & 870 \\
\hline$d=2$ & $t=5$ & 650 & 860 & 570 & 890 & 740 & 620 & 730 & 790 & 570 & 830 & 880 & 700 \\
\hline$d=2$ & $t=6$ & 890 & 860 & 590 & 690 & 770 & 870 & 690 & 550 & 890 & 790 & 860 & 610 \\
\hline$d=3$ & $t=1$ & 740 & 890 & 700 & 810 & 830 & 810 & 870 & 770 & 770 & 880 & 660 & 690 \\
\hline$d=3$ & $t=2$ & 690 & 800 & 780 & 590 & 890 & 650 & 580 & 710 & 710 & 780 & 730 & 850 \\
\hline$d=3$ & $t=3$ & 670 & 830 & 860 & 670 & 870 & 650 & 660 & 860 & 720 & 640 & 780 & 660 \\
\hline$d=3$ & $t=4$ & 840 & 810 & 580 & 760 & 870 & 770 & 810 & 800 & 880 & 740 & 740 & 570 \\
\hline$d=3$ & $t=5$ & 550 & 630 & 800 & 600 & 770 & 890 & 780 & 660 & 650 & 640 & 680 & 670 \\
\hline$d=3$ & $t=6$ & 680 & 600 & 620 & 670 & 720 & 800 & 690 & 750 & 800 & 850 & 850 & 600 \\
\hline
\end{tabular}

Table 12. Time distance between distribution centers and customers (minute).

\begin{tabular}{cccccccc}
\hline \multicolumn{2}{c}{$\boldsymbol{t m}_{\boldsymbol{m} \boldsymbol{j} \boldsymbol{j}}$} & $\boldsymbol{j}=\mathbf{1}$ & $\boldsymbol{j}=\mathbf{2}$ & $\boldsymbol{j}=\mathbf{3}$ & $\boldsymbol{j}=\mathbf{4}$ & $\boldsymbol{j}=\mathbf{5}$ & $\boldsymbol{j}=\mathbf{6}$ \\
\hline$m=1$ & $b=1$ & 0 & 36 & 41 & 30 & 33 & 43 \\
$m=1$ & $b=2$ & 0 & 38 & 45 & 31 & 36 & 40 \\
$m=1$ & $b=3$ & 0 & 34 & 39 & 30 & 32 & 39 \\
$m=2$ & $b=1$ & 0 & 25 & 38 & 26 & 32 & 24 \\
$m=2$ & $b=2$ & 0 & 19 & 42 & 25 & 31 & 27 \\
$m=2$ & $b=3$ & 0 & 25 & 33 & 19 & 28 & 22 \\
$m=3$ & $b=1$ & 0 & 23 & 19 & 27 & 22 & 34 \\
$m=3$ & $b=2$ & 0 & 23 & 42 & 31 & 35 & 27 \\
$m=3$ & $b=3$ & 0 & 31 & 45 & 33 & 37 & 41 \\
\hline
\end{tabular}

Based on the upper and lower bounds of the objective functions, the membership functions of the first and second objective functions are calculated as follows:

$$
\mu_{Z^{\mathrm{cost}}}=\frac{994703700-Z^{\mathrm{cost}}}{994703700}
$$

$$
\mu_{Z_{\text {purchase value }}}=\frac{Z^{\text {purchase value }}}{2943} .
$$

Considering $10 \%$ of the violations for demand, the membership functions for Constraints (18), (19), and (21) are given as follows: 


$$
\begin{aligned}
& \mu_{18}^{+} \\
& =\frac{1.1 \times d m_{p j t}-\sum_{m, b} z_{p m b j t}-i n v t r y_{p j(t-1)}+i n v t r y_{p j t}}{0.1 \times d m_{p j t}}
\end{aligned}
$$

$$
\forall p, j, t>1
$$

$$
\begin{aligned}
& \mu_{18}^{-} \\
& =\frac{\sum_{m, b} z_{p m b j t}+i n v t r y_{p j(t-1)}-i n v t r y_{p j t}-0.9 \times d m_{p j t}}{0.1 \times d m_{p j t}}
\end{aligned}
$$

$$
\forall p, j, t>1
$$

$$
\mu_{19}^{+}=\frac{1.1 \times d m_{p j t}-\sum_{m, b} z_{p m b j t}+i n v t r y_{p j t}}{0.1 \times d m_{p j t}}
$$

$\forall p, j, t=1$,

$$
\mu_{19}^{-}=\frac{\sum_{m, b} z_{p m b j t}-i n v t r y_{p j t}-0.9 \times d m_{p j t}}{0.1 \times d m_{p j t}},
$$

$$
\forall p, j, t=1
$$

$$
\begin{aligned}
\mu_{21}^{+}=\frac{1.1 \times \sum_{t} d m_{p j t}-\sum_{m, b, t} z_{p m b j t}}{0.1 \times \sum_{t} d m_{p j t}} \quad \forall p, j, \\
\mu_{21}^{-}=\frac{\sum_{m, b, t} z_{p m b j t}-0.9 \times \sum_{t} d m_{p j t}}{0.1 \times \sum_{t} d m_{p j t}} \quad \forall p, j .
\end{aligned}
$$

Thus, the fuzzy single-objective mathematical model is as follows:

\section{Mathematical model:}

\section{Objective function}

$\max \alpha$

s.t.:

$\mu_{Z^{\text {cost }}}=\frac{994703700-Z^{\text {cost }}}{994703700} \geq \alpha$,

$\mu_{Z_{\text {purchasevalue }}}=\frac{Z^{\text {purchasevalue }}}{2943} \geq \alpha$

$\mu_{z_{d m}}^{+}=$

$\frac{1.1 \times d m_{p j t}-\sum_{m, b} z_{p m b j t}-i n v t r y_{p j(t-1)}+i n v t r y_{p j t}}{0.1 \times d m_{p j t}}$

$\geq \alpha \quad \forall p, j, t>1$,

$$
\begin{aligned}
& \mu_{z_{d m}}^{-}= \\
& \frac{\sum_{m, b} z_{p m b j t}+i n v t r y_{p j(t-1)}-i n v t r y_{p j t}-0.9 \times d m_{p j t}}{0.1 \times d m_{p j t}} \\
& \geq \alpha \quad \forall p, j, t>1, \\
& \mu_{z_{d m}}^{+}=\frac{1.1 \times d m_{p j t}-\sum_{m, b} z_{p m b j t}+i n v t r y_{p j t}}{0.1 \times d m_{p j t}} \geq \alpha \\
& \forall p, j, t=1, \quad \forall p, j \\
& \mu_{z_{d m}}^{-}=\frac{\sum_{m, b} z_{p m b j t}-i n v t r y_{p j t}-0.9 \times d m_{p j t}}{0.1 \times d m_{p j t}} \geq \alpha \\
& \mu_{21}^{-}=\frac{\sum_{m, b, t} z_{p m b j t}-0.9 \times \sum_{t} d m_{p j t}}{0.1 \times \sum_{t} d m_{p j t}} \quad \forall p, j \\
& \mu_{21}^{+}=\frac{1.1 \times \sum_{t} d m_{p j t}-\sum_{m, b, t} z_{p m b j t}}{0.1 \times \sum_{t} d m_{p j t}} \quad \forall, j=1, \quad
\end{aligned}
$$

During these changes, the objective functions and Constraints (18), (19), and (21) are considered fuzzy and the other constraints are used without any change; of course, they have been excluded here to avoid duplication.

\subsubsection{Results and discussion}

A fuzzy single-objective model was applied to the described case study in GAMS software and CPLEX solver. Based on the obtained results, all four suppliers were chosen to purchase the products from; only the distribution center number 3 was established and then, vehicle 3 was purchased. The values of the objective functions and the maximum fuzzy membership function are reported in Table 13.

One of the operational decisions that makes a significant contribution to distribution of products, particularly perishable products, is the routing of vehicles taken for serving customers. As stated, the model only uses the vehicle number 3 to distribute its products. The route traveled by this vehicle in different

Table 13. Objective functions value.

\begin{tabular}{ccc}
\hline $\boldsymbol{\alpha}$ & $\boldsymbol{Z}^{\text {cost }}$ & $\boldsymbol{Z}^{\text {purchasing value }}$ \\
\hline 0.4444 & 553894500 & 1835.45 \\
\hline
\end{tabular}




\begin{tabular}{|c|c|c|c|c|c|c|}
\hline $\begin{array}{c}a t_{3,5,1}=37 \\
a t_{3,3,2}=129 \\
a t_{3,4,4}=83 \\
a t_{3,3,5}=128\end{array}$ & $\begin{array}{l}a t_{3,4,1}=83 \\
a t_{3,2,2}=167 \\
a t_{3,6,4}=128 \\
a t_{3,2,5}=166\end{array}$ & $\begin{array}{c}a t_{3,3,1}=123 \\
a t_{3,2,3}=31 \\
a t_{3,3,4}=157 \\
a t_{3,6,6}=41\end{array}$ & $\begin{array}{c}a t_{3,2,1}=161 \\
a t_{3,3,3}=68 \\
a t_{3,2,4}=195 \\
a t_{3,5,6}=48\end{array}$ & $\begin{array}{l}a t_{3,6,2}=41 \\
a t_{3,5,3}=88 \\
a t_{3,4,5}=33 \\
a t_{3,2,6}=82\end{array}$ & $\begin{array}{c}a t_{3,4,2}=65 \\
a t_{3,6,3}=116 \\
a t_{3,6,5}=80\end{array}$ & $\begin{array}{c}a t_{3,5,2}=109 \\
a t_{3,5,4}=37 \\
a t_{3,5,5}=108\end{array}$ \\
\hline
\end{tabular}

Box I

$$
\begin{aligned}
& \theta_{11235}=300, \quad \theta_{11336}=350, \quad \theta_{11435}=400, \quad \theta_{12133}=600, \quad \theta_{12236}=500, \quad \theta_{12331}=500 \text {, } \\
& \theta_{12436}=600, \quad \theta_{13134}=600, \quad \theta_{13135}=700, \quad \theta_{13136}=750, \quad \theta_{13231}=700, \quad \theta_{13233}=650 \text {, } \\
& \theta_{13234}=600, \quad \theta_{13332}=550, \quad \theta_{13333}=700, \quad \theta_{13431}=750, \quad \theta_{22133}=600, \quad \theta_{22236}=400 \text {, } \\
& \theta_{22432}=400, \quad \theta_{22435}=650, \quad \theta_{23132}=550, \quad \theta_{23235}=660, \quad \theta_{23231}=800, \quad \theta_{23232}=800 \text {, } \\
& \theta_{23333}=700, \quad \theta_{23332}=700, \quad \theta_{23335}=800, \quad \theta_{23431}=750, \quad \theta_{23434}=800, \quad \theta_{23432}=700 \text {, } \\
& \theta_{23435}=700, \quad \theta_{23436}=800, \quad \theta_{33131}=700, \quad \theta_{33132}=700, \quad \theta_{33135}=700, \quad \theta_{33134}=750 \text {, } \\
& \theta_{33231}=800, \quad \theta_{33233}=650, \quad \theta_{33235}=700, \quad \theta_{33332}=700, \quad \theta_{33333}=700, \quad \theta_{33335}=800 \text {, } \\
& \theta_{33431}=750, \quad \theta_{33433}=650, \quad \theta_{33432}=700, \quad \theta_{33434}=800, \quad \theta_{33435}=700, \quad \theta_{33436}=800 \text {. }
\end{aligned}
$$

\section{Box II}

time periods is given below:

$$
\begin{array}{ll}
t=1 \quad(\hat{c} \rightarrow c): c_{1} \rightarrow c_{5} \rightarrow c_{4} \rightarrow c_{3} \rightarrow c_{2} \rightarrow c_{1}, \\
t=2 \quad(\hat{c} \rightarrow c): c_{1} \rightarrow c_{6} \rightarrow c_{4} \rightarrow c_{5} \rightarrow c_{3} \rightarrow c_{2} \rightarrow c_{1} \\
t=3 \quad(\hat{c} \rightarrow c): c_{1} \rightarrow c_{2} \rightarrow c_{3} \rightarrow c_{5} \rightarrow c_{6} \rightarrow c_{1}, \\
t=4 \quad(\hat{c} \rightarrow c): c_{1} \rightarrow c_{5} \rightarrow c_{4} \rightarrow c_{6} \rightarrow c_{3} \rightarrow c_{2} \rightarrow c_{1} \\
t=5 \quad(\hat{c} \rightarrow c): c_{1} \rightarrow c_{4} \rightarrow c_{6} \rightarrow c_{5} \rightarrow c_{3} \rightarrow c_{2} \rightarrow c_{1} \\
t=6 \quad(\hat{c} \rightarrow c): c_{1} \rightarrow c_{6} \rightarrow c_{5} \rightarrow c_{2} \rightarrow c_{1} .
\end{array}
$$

On the routes, the first customer $\left(c_{1}\right)$ represents the established distribution center, which is the distribution center number 3 . As it can be seen, the vehicle returns to distribution centers after visiting customers.

The arrival time of each vehicle to the customer's location in each time period is determined by using variable $a t_{m j t}$ as presented in Box I.

Other tactical decisions that have a significant impact on the greening of the network and the total cost reduction are the selection of suppliers and the number of orders in each time period. The results show that the purchase of products has been linked to each of the four suppliers, and the order quantity for each supplier of a product per time period is reported as follows. For example, it is shown that the first product purchased at the first price level from supplier 2 by the distribution center number 3 in the time period 5 is 300 units (Box II). The number of products delivered to customers by each vehicle in each time period from the located distribution center is another operational decision $\left(z_{p m b j t}\right)$ (Box III).

Thus, by implementing the proposed model in GAMS software, the optimal values of objective functions and decision variables are calculated. In the network structure of the problem prior to mathematical model development, the distribution center 2 and Vehicles 1 and 3 were used. The total cost was 643927300 and the purchasing value of green suppliers was 1794.6. By implementing the proposed model, the total cost of the network decreased by more than $16 \%$ and the value of purchasing from green suppliers increased by more than $2 \%$, which implies the suitable performance and effectiveness of the proposed model.

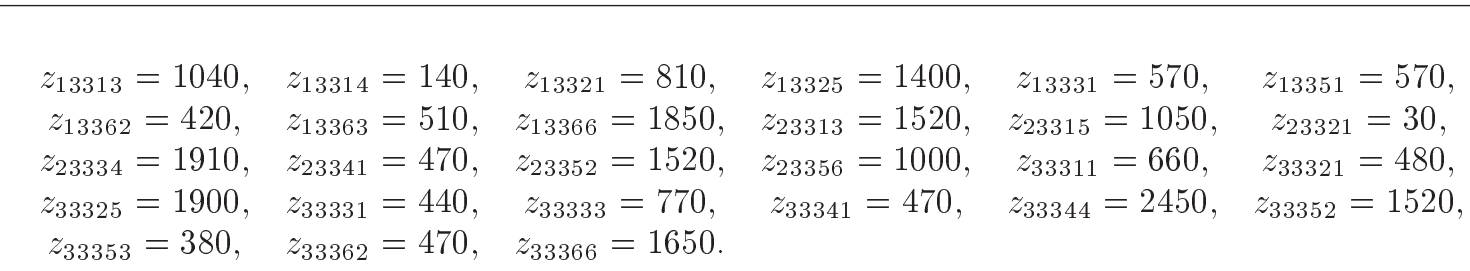


Table 14. Obtained results from demand decrease scenarios.

\begin{tabular}{cccc}
\hline Scenario & Number of demands & $\boldsymbol{Z}^{\text {cost }}$ & $\boldsymbol{Z}^{\text {purchasing value }}$ \\
\hline 1 & $0.70 \times$ demands & 435765200 & 1831.30 \\
2 & $0.75 \times$ demands & 443216400 & 1813.25 \\
3 & $0.80 \times$ demands & 456257100 & 1634.72 \\
4 & $0.85 \times$ demands & 473571000 & 1787.58 \\
5 & $0.90 \times$ demands & 499961500 & 1684.30 \\
6 & $0.95 \times$ demands & 531682400 & 1673.87 \\
\hline
\end{tabular}

Table 15. Obtained results from demand increase scenarios.

\begin{tabular}{cccc}
\hline Scenario & Number of demands & $\boldsymbol{Z}^{\text {cost }}$ & $\boldsymbol{Z}^{\text {purchasing value }}$ \\
\hline 1 & $1.05 \times$ demands & 572479800 & 1527.58 \\
2 & $1.10 \times$ demands & 610787000 & 1572.30 \\
3 & $1.15 \times$ demands & 673477200 & 1576.57 \\
4 & $1.20 \times$ demands & 714641100 & 1540.76 \\
5 & $1.25 \times$ demands & 751823800 & 1525.54 \\
6 & $1.30 \times$ demands & 784813900 & 1528.67 \\
\hline
\end{tabular}

\section{Sensitivity analysis}

For the validation of the proposed model, its sensitivity to some parameters was measured. To this end, some scenarios should be defined. Applying each scenario, we examine to what extent our expectations of the model are consistent with the achieved results. For this purpose, two scenarios have been applied. The first set of scenarios is based on decreasing demands, while the second set is based on increasing demands.

\subsection{Demand decrease scenario}

In this section, scenarios are applied based on decreasing demands. If the demands decrease, the costs will not increase. However, the level of greenness would not increase, which is confirmed by the results of sensitivity analysis. Hence, one cannot express a decisive opinion about the greenness of the objective function. In other words, there is no way to prove a conflict between the green objective function and cost objective functions. In fact, the reason for incorporating this function in the model is only to satisfy the environmental needs, respect human rights, and obey the environmental rules and requirements. However, it is absolutely impossible to discuss greenness of the objective function. As a result, scenarios of decreasing demand and the achieved results are shown in Table 14 and Figures 1 and 2 .

\subsection{Demand increase scenario}

The model is expected to bring about inverse results with demand decrease as a result of increasing the

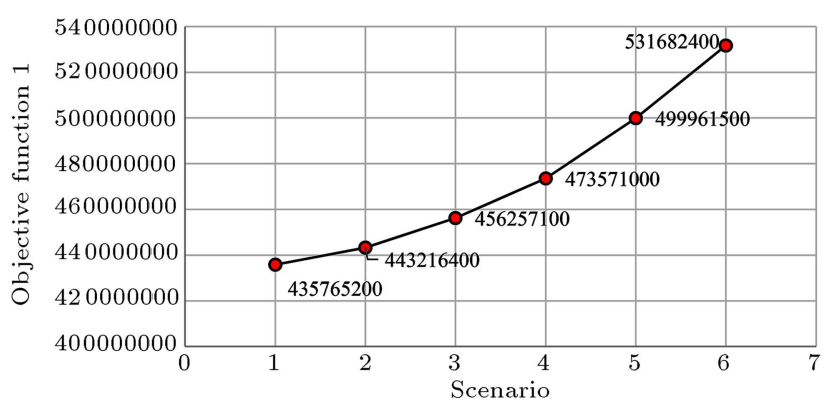

Figure 1. Results of demand decrease scenarios for objective function 1 .

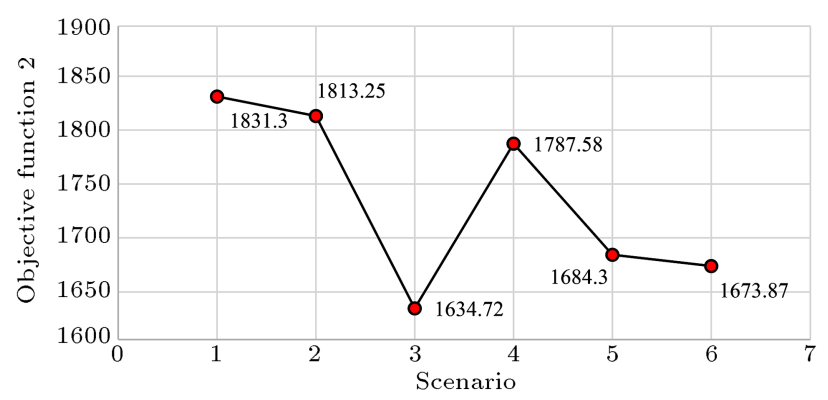

Figure 2. Results of demand decrease scenarios for objective function 2 .

demands. Thus, the results obtained from the model implementation are illustrated in Table 15 and Figures 3 and 4 .

The results obtained from the sensitivity analysis of the model under two scenarios of demand decrease 


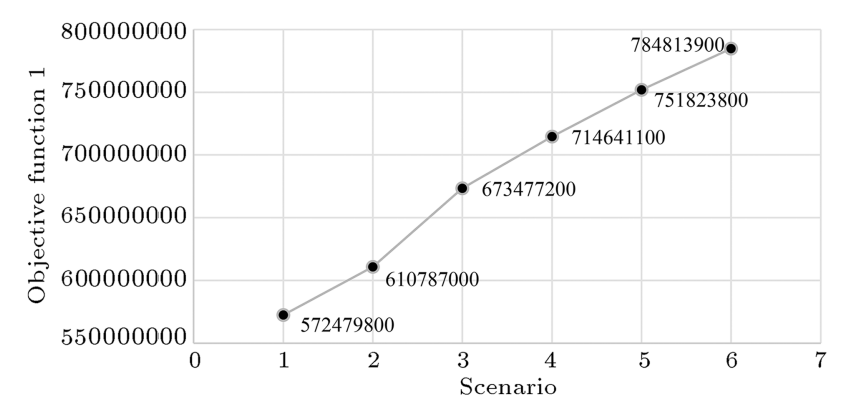

Figure 3. Results of demand increase scenarios for objective function 1 .

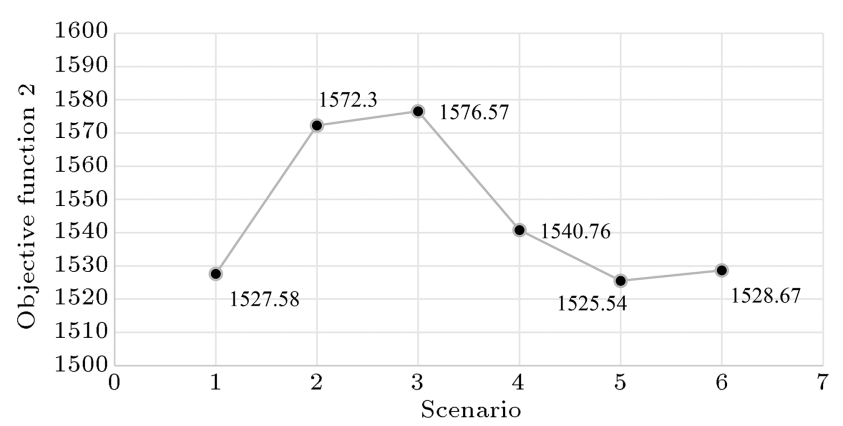

Figure 4. Results of demand increase scenarios for objective function 2 .

and demand increase are consistent with our expectations of the model. Hence, it is possible to use these results to validate the model.

\section{Conclusion}

In today's competitive market, the purchasing process, especially supplier selection, is a very important challenge for companies to succeed. Since supplier is the first layer in a chain, any shortcoming in this layer will also affect other layers. In order to make a suitable decision regarding supplier selection and order allocation, this study developed a two-stage approach based on Fuzzy Analytic Hierarchy Process (FAHP) and Multi-Objective Mixed Integer Linear Programming (MOMILP) model under uncertainty.

The data from a pharmaceutical supply chain was used to evaluate the efficiency of the proposed approach and a fuzzy solution approach was employed to solve the bi-objective model with uncertain demands. Implementation of the proposed model resulted in a $16 \%$ reduction in total costs and a $2 \%$ increase in purchasing value of green suppliers. Also, the behavior of the proposed model for the scenarios caused by the sensitivity analysis of the demand parameter indicates the proper functionality of the proposed model.

As for future research, it is suggested that new Multiple Attribute Decision-Making (MADM) methods such as robust Best-Worst Method (BWM) and fuzzy BWM be used to evaluate suppliers, and because the model presented here is placed in the NP-hard issues category, it is recommended that large-scale algorithms be employed to solve large-scale problems.

\section{References}

1. http://www.worldometers.info.

2. Wan, S.P., Xu, G.L., and Dong, J.Y. "Supplier selection using ANP and ELECTRE II in interval 2tuple linguistic environment", Information Sciences, 385, pp. 19-38 (2017).

3. Lo, H.W., Liou, J.J., Wang, H.S., and Tsai, Y.S. "An integrated model for solving problems in green supplier selection and order allocation", Journal of Cleaner Production, 190, pp. 339-352 (2018).

4. Lu, L.Y., Wu, C.H., and Kuo, T.C. "Environmental principles applicable to green supplier evaluation by using multi-objective decision analysis", International Journal of Production Research, 45(18-19), pp. 43174331 (2007).

5. Mirzaee, H., Naderi, B., and Pasandideh, S.H.R. "A preemptive fuzzy goal programming model for generalized supplier selection and order allocation with incremental discount", Computers \& Industrial Engineering, 122, pp. 292-302 (2018).

6. Mina, H., Mirabedini, S.N., Kian, H., and Ghaderi, S.F. "A new two stage integrated approach for green supplier selection", Applied Mathematics in Engineering, Management and Technology, 1(1), pp. 1247-1126 (2014).

7. Garg, H. and Kumar, K. "A novel exponential distance and its based TOPSIS method for interval-valued intuitionistic fuzzy sets using connection number of SPA theory", Artificial Intelligence Review, 53(1), pp. 595-624 (2020).

8. Garg, H. "Intuitionistic fuzzy hamacher aggregation operators with entropy weight and their applications to multi-criteria decision-making problems", Iranian Journal of Science and Technology, Transactions of Electrical Engineering, 43(3), pp. 597-613 (2019).

9. Garg, H. "Hesitant pythagorean fuzzy Maclaurin symmetric mean operators and its applications to multiattribute decision-making process", International Journal of Intelligent Systems, 34(4), pp. 601-626 (2019).

10. Arora, R. and Garg, H. "Group decision-making method based on prioritized linguistic intuitionistic fuzzy aggregation operators and its fundamental properties", Computational and Applied Mathematics, 38(2), p. 36 (2019).

11. Sarkar, S., Pratihar, D.K., and Sarkar, B. "An integrated fuzzy multiple criteria supplier selection approach and its application in a welding company", Journal of Manufacturing Systems, 46, pp. 163-178 (2018).

12. Guarnieri, P. and Trojan, F. "Decision making on supplier selection based on social, ethical, and environmental criteria: A study in the textile industry", Resources, Conservation and Recycling, 141, pp. 347361 (2019). 
13. Kannan, D., Khodaverdi, R., Olfat, L., Jafarian, A., and Diabat, A. "Integrated fuzzy multi criteria decision making method and multi-objective programming approach for supplier selection and order allocation in a green supply chain", Journal of Cleaner Production, 47, pp. 355-367 (2013).

14. Govindan, K. and Sivakumar, R. "Green supplier selection and order allocation in a low-carbon paper industry: integrated multi-criteria heterogeneous decision-making and multi-objective linear programming approaches", Annals of Operations Research, 238(1-2), pp. 243-276 (2016).

15. Hamdan, S. and Cheaitou, A. "Dynamic green supplier selection and order allocation with quantity discounts and varying supplier availability", Computers \& Industrial Engineering, 110, pp. 573-589 (2017).

16. Yousefi, S., Rezaee, M.J., and Solimanpur, M. "Supplier selection and order allocation using twostage hybrid supply chain model and game-based order price", Operational Research, pp. 1-36 (2019). https://doi.org/10.1007/s12351-019-00456-6

17. Mohammed, A., Setchi, R., Filip, M., Harris, I., and $\mathrm{Li}, \mathrm{X}$. "An integrated methodology for a sustainable two-stage supplier selection and order allocation problem", Journal of Cleaner Production, 192, pp. 99-114 (2018).

18. Ghodsypour, S.H. and O'Brien, C. "A decision support system for supplier selection using an integrated analytic hierarchy process and linear programming", International Journal of Production Economics, 56, pp. 199-212 (1998).

19. Kokangul, A. and Susuz, Z. "Integrated analytical hierarch process and mathematical programming to supplier selection problem with quantity discount", Applied Mathematical Modelling, 33(3), pp. 1417-1429 (2009).

20. Mina, H., Mirabedin, S.N., and Pakzad-Moghadam, S.H. "An integrated fuzzy analytic network process approach for green supplier selection: A case study of petrochemical industry", Management Science and Practice, 2(2), pp. 31-47 (2014).

21. Tavana, M., Yazdani, M., and Di Caprio, D. "An application of an integrated ANP-QFD framework for sustainable supplier selection", International Journal of Logistics Research and Applications, 20(3), pp. 254275 (2017).

22. Gupta, H. and Barua, M.K. "Supplier selection among SMEs on the basis of their green innovation ability using BWM and fuzzy TOPSIS", Journal of Cleaner Production, 152, pp. 242-258 (2017).

23. Jain, V., Sangaiah, A.K., Sakhuja, S., Thoduka, N., and Aggarwal, R. "Supplier selection using fuzzy AHP and TOPSIS: a case study in the Indian automotive industry", Neural Computing and Applications, 29(7), pp. 555-564 (2018).

24. Mahmoudi, A., Sadi-Nezhad, S., and Makui, A. "An extended fuzzy VIKOR for group decision-making based on fuzzy distance to supplier selection", Scientia Iranica, Transaction E, Industrial Engineering, 23(4), p. 1879 (2016).

25. Awasthi, A., Govindan, K., and Gold, S. "Multitier sustainable global supplier selection using a fuzzy AHP-VIKOR based approach", International Journal of Production Economics, 195, pp. 106-117 (2018).

26. Liu, K., Liu, Y., and Qin, J. "An integrated ANPVIKOR methodology for sustainable supplier selection with interval type-2 fuzzy sets", Granular Computing, 3(3), pp. 193-208 (2018).

27. Gören, H.G. "A decision framework for sustainable supplier selection and order allocation with lost sales", Journal of Cleaner Production, 183, pp. 1156-1169 (2018).

28. Liu, T., Deng, Y., and Chan, F. "Evidential supplier selection based on DEMATEL and game theory", International Journal of Fuzzy Systems, 20(4), pp. 1321-1333 (2018).

29. Soto, A.V., Chowdhury, N.T., Allahyari, M.Z., Azab, A., and Baki, M.F. "Mathematical modeling and hybridized evolutionary LP local search method for lot-sizing with supplier selection, inventory shortage, and quantity discounts", Computers \& Industrial Engineering, 109, pp. 96-112 (2017).

30. Cheraghalipour, A. and Farsad, S. "A bi-objective sustainable supplier selection and order allocation considering quantity discounts under disruption risks: A case study in plastic industry", Computers \& Industrial Engineering, 118, pp. 237-250 (2018).

31. Hu, H., Xiong, H., You, Y., and Yan, W. "A mixed integer programming model for supplier selection and order allocation problem with fuzzy multi objective", Scientific Programming, pp. 1-13 (2016). https://doi.org/10.1155/2016/9346781

32. Amin, S.H. and Zhang, G. "An integrated model for closed-loop supply chain configuration and supplier selection: Multi-objective approach", Expert Systems with Applications, 39(8), pp. 6782-6791 (2012).

33. Moheb-Alizadeh, H. and Handfield, R. "An integrated chance-constrained stochastic model for efficient and sustainable supplier selection and order allocation", International Journal of Production Research, 56(21), pp. 6890-6916 (2018).

34. Nourmohamadi Shalke, P., Paydar, M.M., and Hajiaghaei-Keshteli, M. "Sustainable supplier selection and order allocation through quantity discounts", International Journal of Management Science and Engineering Management, 13(1), pp. 20-32 (2018).

35. Bafrooei, A.A., Mina, H., and Ghaderi, S.F. "A supplier selection problem in petrochemical industry using common weight data envelopment analysis with qualitative criteria", International Journal of Industrial and Systems Engineering, 18(3), pp. 404-417 (2014).

36. De Boer, L., Labro, E., and Morlacchi, P. "A review of methods supporting supplier selection", European 
Journal of Purchasing \& Supply Management, 7(2), pp. $75-89$ (2001).

37. Aissaoui, N., Haouari, M., and Hassini, E. "Supplier selection and order lot sizing modeling: A review", Computers \& Operations Research, 34(12), pp. 35163540 (2007).

38. Ho, W., Xu, X., and Dey, P.K. "Multi-criteria decision making approaches for supplier evaluation and selection: A literature review", European Journal of Operational Research, 202(1), pp. 16-24 (2010).

39. Ware, N., Sing, S., and Banwet, D. "Supplier selection problem: A state-of-the-art review", Management Science Letters, 2(5), pp. 1465-1490 (2012).

40. Chai, J., Liu, J.N., and Ngai, E.W. "Application of decision-making techniques in supplier selection: A systematic review of literature", Expert Systems with Applications, 40(10), pp. 3872-3885 (2013).

41. Igarashi, M., de Boer, L., and Fet, A.M. "What is required for greener supplier selection? A literature review and conceptual model development", Journal of Purchasing and Supply Management, 19(4), pp. 247263 (2013).

42. Govindan, K., Rajendran, S., Sarkis, J., and Murugesan, P. "Multi criteria decision making approaches for green supplier evaluation and selection: a literature review", Journal of Cleaner Production, 98, pp. 66-83 (2015).

43. Zimmer, K., Fröhling, M., and Schultmann, F. "Sustainable supplier management-a review of models supporting sustainable supplier selection, monitoring and development", International Journal of Production Research, 54(5), pp. 1412-1442 (2016).

44. Keshavarz Ghorabaee, M., Amiri, M., Zavadskas, E.K., and Antucheviciene, J. "Supplier evaluation and selection in fuzzy environments: A review of MADM approaches", Economic Research-Ekonomska istraživanja, 30(1), pp. 1073-1118 (2017).

45. Mafakheri, F., Breton, M., and Ghoniem, A. "Supplier selection-order allocation: A two-stage multiple criteria dynamic programming approach", International Journal of Production Economics, 132(1), pp. 52-57 (2011).

46. Shaw, K., Shankar, R., Yadav, S.S., and Thakur, L.S. "Supplier selection using fuzzy AHP and fuzzy multiobjective linear programming for developing low carbon supply chain", Expert Systems with Applications, 39(9), pp. 8182-8192 (2012).

47. Azadnia, A.H., Saman, M.Z.M., and Wong, K.Y. "Sustainable supplier selection and order lot-sizing: An integrated multi-objective decision-making process", International Journal of Production Research, 53(2), pp. 383-408 (2015).
48. Hamdan, S. and Cheaitou, A. "Green supplier selection and order allocation using an integrated fuzzy TOPSIS, AHP and IP approach", In 2015 International Conference on Industrial Engineering and Operations Management (IEOM), pp. 1-10. IEEE March 2015).

49. Hamdan, S. and Cheaitou, A. "Supplier selection and order allocation with green criteria: An MCDM and multi-objective optimization approach", Computers \& Operations Research, 81, pp. 282-304 (2017).

50. Babbar, C. and Amin, S.H. "A multi-objective mathematical model integrating environmental concerns for supplier selection and order allocation based on fuzzy QFD in beverages industry", Expert Systems with Applications, 92, pp. 27-38 (2018).

51. Dağdeviren, M. and Yüksel, İ. "A fuzzy analytic network process (ANP) model for measurement of the sectoral competititon level (SCL)", Expert Systems with Applications, 37(2), pp. 1005-1014 (2010).

52. Qazvini, Z.E., Amalnick, M.S., and Mina, H. "A green multi-depot location routing model with splitdelivery and time window", International Journal of Management Concepts and Philosophy, 9(4), pp. 271$282(2016)$.

53. Rani, D., Gulati, T.R., and Garg, H. "Multi-objective non-linear programming problem in intuitionistic fuzzy environment: Optimistic and pessimistic view point", Expert Systems with Applications, 64, pp. 228-238 (2016).

54. Zimmermann, H.J. "Fuzzy programming and linear programming with several objective functions", Fuzzy Sets and Systems, 1(1), pp. 45-55 (1978).

55. Torabi, S.A. and Hassini, E. "An interactive possibilistic programming approach for multiple objective supply chain master planning", Fuzzy Sets and Systems, 159(2), pp. 193-214 (2008).

56. Lin, R.H. "An integrated model for supplier selection under a fuzzy situation", International Journal of Production Economics, 138(1), pp. 55-61 (2012).

57. Garg, H., Rani, M., Sharma, S.P., and Vishwakarma, Y. "Intuitionistic fuzzy optimization technique for solving multi-objective reliability optimization problems in interval environment", Expert Systems with Applications, 41(7), pp. 3157-3167 (2014).

58. Garg, H., Rani, M., Sharma, S.P., and Vishwakarma, $Y$. "Bi-objective optimization of the reliabilityredundancy allocation problem for series-parallel system", Journal of Manufacturing Systems, 33(3), pp. 335-347 (2014).

59. Luthra, S., Govindan, K., Kannan, D., Mangla, S.K., and Garg, C.P. "An integrated framework for sustainable supplier selection and evaluation in supply chains", Journal of Cleaner Production, 140, pp. 16861698 (2017).

60. Fallahpour, A., Olugu, E.U., Musa, S.N., Wong, K.Y., and Noori, S. "A decision support model for sustainable supplier selection in sustainable supply chain management", Computers \& Industrial Engineering, 105, pp. 391-410 (2017). 
61. Büyüközkan, G. and Çifçi, G. "A novel fuzzy multicriteria decision framework for sustainable supplier selection with incomplete information", Computers in Industry, 62(2), pp. 164-174 (2011).

62. Kannan, D., Govindan, K., and Rajendran, S. "Fuzzy axiomatic design approach based green supplier selection: a case study from Singapore", Journal of Cleaner Production, 96, pp. 194-208 (2015).

63. Noci, G. “Designing 'green' vendor rating systems for the assessment of a supplier's environmental performance", European Journal of Purchasing \& Supply Management, 3(2), pp. 103-114 (1997).

64. Humphreys, P., McIvor, R., and Chan, F. "Using casebased reasoning to evaluate supplier environmental management performance", Expert Systems with Applications, 25(2), pp. 141-153 (2003).

65. Lee, A.H., Kang, H.Y., Hsu, C.F., and Hung, H.C. "A green supplier selection model for high-tech industry", Expert Systems with Applications, 36(4), pp. 79177927 (2009).

66. Handfield, R., Walton, S.V., Sroufe, R., and Melnyk, S.A. "Applying environmental criteria to supplier assessment: a study in the application of the analytical hierarchy process", European Journal of Operational Research, 141(1), pp. 70-87 (2002).

67. Feyziog̃lu, O. and Büyüközkan, G. "Evaluation of green suppliers considering decision criteria dependencies" In Multiple Criteria Decision Making for Sustainable Energy and Transportation Systems, pp. 145-154, Springer, Berlin, Heidelberg (2010).

68. Yang, Y. and Wu, L. "Grey entropy method for green supplier selection", In 2007 International Conference on Wireless Communications, Networking and Mobile Computing, pp. 4682-4685, IEEE (Sept. 2007).

\section{Biographies}

Zahra Ebrahimi Qazvini holds a Master of Science in Industrial Engineering from Department of Industrial and Systems Engineering, Payam Noor University of Tehran. Formerly, she was an undergraduate student of Industrial Engineering at the Islamic Azad University of Varamin-Pishva. Her main research interests are focused on operations research, simulation, simulation, performance evaluation, and supply chain management. She has also published some notable papers in those areas in international and domestic journals as well as conference proceedings.

Alireza Haji received his PhD in Industrial Engineering from Sharif University of Technology, Iran. He is an Associate Professor at the Department of Industrial Engineering of Sharif University of Technology. His research interests are inventory management and control, production scheduling, stochastic process and project management and scheduling. He has published a lot of papers in national and international journals and conference proceedings.

Hassan Mina is a graduated Master student of Socio-Economic Systems Engineering, Department of Industrial and Systems Engineering at University of Tehran. Formerly, he was an undergraduate student of Industrial Engineering-Industrial Production at the Isfahan University of Technology. As a top student in Master study, his main research interests are focused on operations research, scheduling, supplier selection, green supply chain, and multi-criteria decision-making. He also has published some notable papers in those areas in international and domestic journals as well as conference proceedings. 